\title{
Konzert für einen Engel
}

\author{
E. Taverna
}

Kann das gutgehen, wenn Mediziner Kriminalromane schreiben? Patricia Highsmith entwickelte eine Poetologie des Thrillers, worin sie behauptete, dass der Autor eines Krimi wissen müsse, was im Kopf eines Verbrechers vorgehe, was er aber nur könne, wenn er Mitgefühl aufbringe. An Einfühlungsvermögen und Kenntnissen fehlt es Enrico Danieli nicht. Er ist in Zürich als Arzt tätig und betitelt seinen neusten Roman "Konzert für einen Engel». Darin kommen eine schöne Leiche vor und eine Landpraxis, Leidenschaften und Intrigen. Danieli nützt geschickt seine eigene Berufserfahrung, wobei, so hoffen wir wenigstens, auf ihn nicht zutrifft, was Dürrrenmatts Schriftsteller im Hörspiel "Abendstunde im Spätherbst" seinem Opfer erklärt: "Sie haben mir die Idee zu einem Hörspiel gegeben, und nun müssen sie sterben, denn ich schreibe nur, was ich erlebe, weil ich überhaupt keine Phantasie besitze, weil ich nur schreiben kann, was ich erlebe."

Die folgende Leseprobe eröffnet die Erzählung mit dem Kapitel "Ein erster Tag», eine Geschichte, die unerbittlich wie ein Uhrzeiger auf das Finale des siebten Tages vorrückt.

«Langsam fuhren die roten Wagen der Bergbahn durch eine sanft ansteigende Hügellandschaft. Sie hatten Verspätung. Unruhig und etwas irritiert schaute Doktor Riccardo von Wyl auf seine Uhr. Wenn sie mich nur abholen, dachte er, ich würde das Haus allein nicht mehr finden. Vor vielen Jahren, erinnerte er sich, hatte er seinen Kollegen schon einmal hier besucht. Sein linkes Augenlid zuckte, wehrlos war er diesem lästigen Muskelkrampf ausgesetzt. Wieder hielt der Zug bei einem verlassenen Stationsgebäude, niemand stieg ein, niemand stieg aus. Der Himmel war von einem zarten, dunstigen Blau, und Windstösse gingen durch die entlaubten Äste der Bäume. Weiter in der Höhe waren die Berge schneebedeckt. Es waren nur wenige Fahrgäste unterwegs an diesem Samstag im November. Im hinteren Abteil sass ein schwergewichtiger Mann in einem dunklen Lodenmantel und sog an einem erloschenen Stumpen, ihm gegenüber sah er dünne, lange Beine, die einem kleinen, weissen Hund als Schlafplatz dienten. Den Kopf der Frau konnte Dr. von Wyl - mit Vornamen Richard, seit einem längeren Italienaufenthalt von seinen Kollegen spöttisch Riccardo genannt - nicht erkennen. Sie muss jung sein, dachte er, so schlanke Beine hat keine ältere Frau. Endlich fuhren sie weiter und näherten sich dem Ziel.»

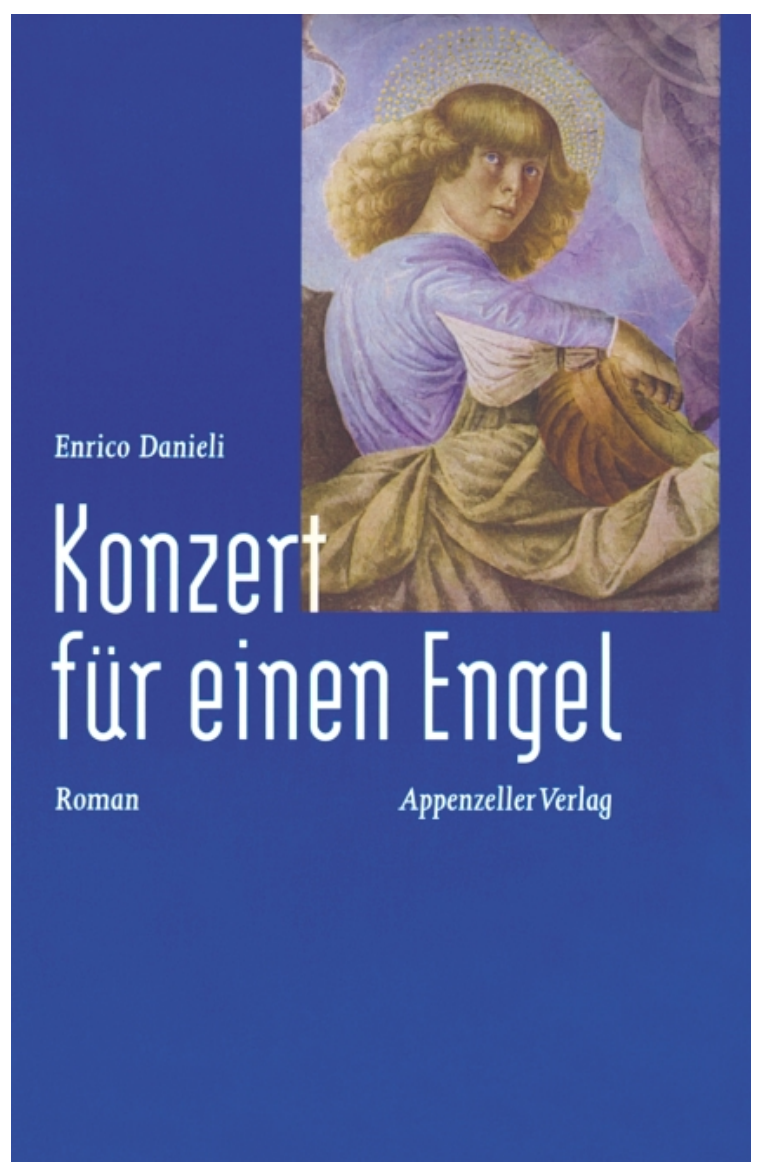

Danieli ist auch ein guter Kenner von Land und Leuten, die der reisende von Wyl, als Praxisvertreter seines Freundes, während einer Woche kennenlernen wird. Das hügelige Land mit seinen vielen Eigenheiten ist gut getroffen, das dörfliche Vereinsleben und die abgelegenen Orte mit ihren zahlreichen Heimen für Alte, Asylanten und Sekten sind typisch für die Gegend. Eine Angela tritt auf, engelhaft schön, mit einschlägiger Anamnese und zahlreichen heimlichen und unheimlichen Verehrern. Auch von Wyl erliegt ihrer geheimnisvollen, morbiden Ausstrahlung, was ihn zu einem fatalen Kunstfehler verführt. Überhaupt ist dieser Kollege nicht mehr ganz auf der Höhe seiner Kunst, scheint aber für toxikologische Probleme ein besonderes Gespür zu haben. Die Geschichte erzählt von einem Verbrechen und von einem drohenden Rufmord, von einer Männerfreundschaft und dem Alltag einer ländlichen Praxis, irgendwo im Osten der Schweiz. Wer das alles genauer wissen möchte, lasse sich dieses Buch zu Weihnachten schenken.

Enrico Danieli. Konzert für einen Engel. Herisau: Appenzeller Verlag; 2000. 179 Seiten. 